\title{
Comparative efficacy evaluation of inverted internal limiting membrane flap technique and internal limiting membrane peeling in large macular holes: a systematic review and meta-analysis
}

\author{
Yu Shen ${ }^{1,2}$ (D) Xiaoqin Lin ${ }^{2}$, Luyi Zhang ${ }^{2}$ and Miaoqin $\mathrm{Wu}^{2^{*}}$ (1)
}

\begin{abstract}
Background: The purpose of this study was to compare the anatomical and visual outcomes of inverted internal limiting membrane (ILM) flap technique and internal limiting membrane peeling in large macular holes (MH).

Methods: Related studies were reviewed by searching electronic databases of Pubmed, Embase, Cochrane Library. We searched for articles that compared inverted ILM flap technique with ILM peeling for large MH (> $400 \mu \mathrm{m})$. Double-arm meta-analysis was performed for the primary end point that was the rate of $\mathrm{MH}$ closure, and the secondary end point was postoperative visual acuity (VA). Heterogeneity, publication bias, sensitivity analysis and subgroup analysis were conducted to guarantee the statistical power.

Results: This review included eight studies involving 593 eyes, 4 randomized control trials and 4 retrospective studies. After sensitivity analysis for eliminating the heterogeneity of primary outcome, the pooled data showed the rate of $\mathrm{MH}$ closure with inverted ILM flap technique group was statistically significantly higher than ILM peeling group (odds ratio $(O R)=3.95$, 95\% confidence interval $(C I)=1.89$ to $8.27 ; P=0.0003$ ). At the follow-up duration of 3 months, postoperative VA was significantly better in the group of inverted ILM flap than ILM peeling (mean difference (MD) $=-0.16,95 \% \mathrm{Cl}=-0.23$ to $0.09 ; P<0.00001)$. However, there was no difference in visual outcomes between the two groups of different surgical treatments at relatively long-term follow-up over 6 months $(M D=0.01,95 \% \mathrm{Cl}=-0.12$ to $0.15 ; P=0.86)$.

Conclusion: Vitrectomy with inverted ILM flap technique had a better anatomical outcome than ILM peeling. Flap technique also had a signifcant visual gain in the short term, but the limitations in visual recovery at a longer follow-up was found.
\end{abstract}

Keywords: Inverted internal limiting membrane flap technique, Internal limiting membrane peeling, Large macular hole, Meta-analysis

\footnotetext{
* Correspondence: eyewmq@126.com

²Department of Ophthalmology, Zhejiang Provincial People's Hospital,

People's Hospital of Hangzhou Medical college, Hangzhou 310014 Zhejiang

Province, People's Republic of China

Full list of author information is available at the end of the article
}

(c) The Author(s). 2020 Open Access This article is distributed under the terms of the Creative Commons Attribution 4.0 International License (http://creativecommons.org/licenses/by/4.0/) which permits unrestricted use, distribution, and reproduction in any medium, provided you give appropriate credit to the original author(s) and the source, provide a link to the Creative Commons license, and indicate if changes were made. The Creative Commons Public Domain Dedication waiver (http://creativecommons.org/publicdomain/zero/1.0/) applies to the data made available in this article, unless otherwise stated. 


\section{Background}

Macular hole $(\mathrm{MH})$ is an anatomical defect in the fovea of retina that cause severe visual impairment. It was regarded as an untreatable disease in poor prognosis until the first describtion of vitrectomy to treat $\mathrm{MH}$ by Kelly and Wendel [1] in 1991. The success rate of MH surgery increased to 98\% [2-4] of cases with the introduction of internal limiting membrane (ILM) peeling by Eckardt et al. [5], which was thought to be one of the most effective surgical procedures [6]. However, the anatomical success rate of $\mathrm{MH}$ that are larger than $400 \mu \mathrm{m}$ is less likely to close and has been as low as $40 \%[7,8]$, regardless of whether the ILM has been removed or not during vitrectomy. Michalewska et al. [9] first presented a novel technique of inverted ILM flap for the treatment of large $\mathrm{MH}$, contributing to a relatively high $\mathrm{MH}$ closure rates. Recently, a number of clinical studies have suggested that inverted ILM flap technique achieved better anatomical and visual outcomes than ILM peeling [10-15]. However because of lacking appropriate controls, uncontrollable elements, or insufficient samples in most of these studies, the reliable evidences to support such a view were limited. As far as we know, doublearm study to compare anatomical and visual outcomes between these two methods in MH larger than $400 \mu \mathrm{m}$ have not been systematically reviewed and published. Thus, we conducted a comprehensive meta-analysis to evaluate the efficacy of vitrectomy with inverted ILM flap technique and ILM peeling.

\section{Methods}

\section{Search strategy}

We cautiously searched for studies that used inverted ILM flap technique or ILM peeling to treat $\mathrm{MH}$ larger than $400 \mu \mathrm{m}$. The Pubmed, Embase, Cochrane Library databases were systematically searched for all articles including relevant prospective and retrospective clinical trials published before December 2018. The terms used for systematic search were: (macular hole OR macula hole OR MH OR macular break OR macular fissure OR retinal perforations OR retinal break OR retinal hole OR retinal tear) AND (inner limiting membrane OR internal limiting membrane OR ILM OR limiting membrane) AND (peeling OR peel OR removal OR IP OR SIP) AND (inverted OR inversion OR invert OR flap OR flap technique OR IF OR IFT). Furthermore, We enlarged retrieval coverage and manually searched reference lists of original studies, gray literatures and records, without language or publication year restrictions.

\section{Inclusion and exclusion criteria}

All abstracts, studies and citations were reviewed and assessed. The inclusion criteria for eligibility were as follows: (1) double-arm studies; (2) studies included cases among patients with $\mathrm{MH}$ larger than $400 \mu \mathrm{m}$ who had been treated with the inverted ILM flap technique or ILM peeling; (3) anatomical hole closure rate and visual acuity (VA) were observed after the treatments; (4) the relevant statistics were provided, such as age, gender, duration of disease, hole size, and follow-up time; (5) prospective randomized control trial or retrospective case series. Exclusion criteria were as follows: (1) non - controlled study; (2) patients with macular retinoschisis, age-related macular degeneration, retinal detachment, or proliferative diabetic retinopathy; (3) treatments with modified inverted ILM flap techniques; (4) short -term follow-up that less than three months; (5) reviews or case reports.

\section{Data extraction}

Data were independently extracted and reviewed from each included study by two reviewers (YS and XQL). Any discrepancy between data extractions were resolved by the discussion or consulted by the expert. The following data were extracted: first author, year of publication, type of trials, country, surgical procedure, number of eyes involved, patient demographics, age, duration of disease, minimum diameter of $\mathrm{MH}$, hole closure rate, preoperative and postoperative VA, and follow-up time.

\section{Quality of assessment}

This review included eight studies: 4 randomized control trials (RCTs) and 4 retrospective case series. The included RCTs were evaluated for quality in accordance with the "risk of bias" tool recommended by the Cochrane Handbook 5.1.0 [16].Seven items were assessed: "random sequence generation," "allocation concealment," "blinding of participants and personnel," "blinding of outcome assessment," "incomplete outcome data," "selective reporting," and "other bias." According to whether the included studies fully meet the above criteria, we assessed the quality of trials. The methodological quality of each study was assessed based on the Newcastle-Ottawa Scale (NOS) [17] (range, 0 to 9 stars) for quality of case control studies in meta-analysis. Studies were rated in three areas, including selection, comparability and exposure. Scores $\geq 5$ indicated that the quality of research were relatively high. All items were independently assessed by two investigators (YS and $\mathrm{XQL}$ ), with consensus reached after discussion or expert consultation.

\section{Statistical analysis}

Data analysis was collated and analyzed by Review Manager 5.3 software (RevMan 5.3, The Cochrane Collaboration, Oxford, UK). For the rate of $\mathrm{MH}$ closure, odds ratios (ORs) and 95\% confidence intervals $(\mathrm{Cl})$ were calculated by using Mantel-Haenszel $(\mathrm{M}-\mathrm{H})$ method. To compare the evaluation of VA, the mean difference (MD) of preoperative and postoperative measurements between the two surgical treatments were compared 
using weighted MD and 95\% CI. The sofeware estimated statistical heterogeneity among studies using $\mathrm{I}^{2}$ statistic. When $\mathrm{I}^{2}>50 \%$, it suggested there was significant heterogeneity. A random-effects model was used for data synthesis in the presence of significant heterogeneity, while a fixed-effects model was used when there was no significant heterogeneity. The results of meta - analysis was visually examined by forest plot, and the potential publication bias was showed by funnel plot. $P<0.05$ was considered statistically significant.

\section{Results}

\section{Selection of studies}

Totally, 278 articles were initially searched from electronic databases. 206 studies were left for further analysis after duplications, case reports and reviews removed. The titles and abstracts reviewed, and the remaining 16 studies were retrieved for the next review. Finally, after reading carefully of full-texts, We included a total of 8 studies [4, 9-15], 4 RCTs [4, 911] and 4 case series [12-15]. Fig. 1. depicts the search process.

\section{Records identified through datebase searching}

$$
(\mathrm{n}=278)
$$

Pubmed: $\mathrm{n}=64$ Embase: $\mathrm{n}=116$

Cochrane library: $\mathrm{n}=98$

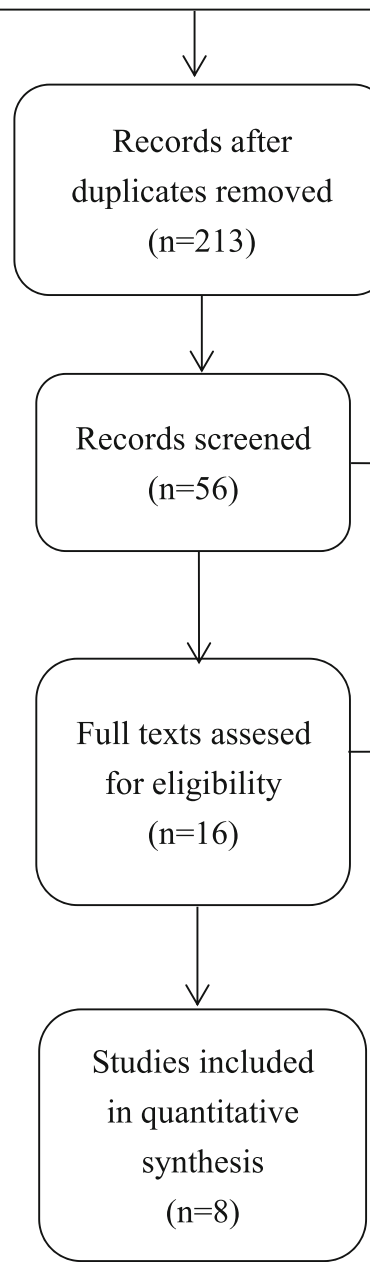

Records excluded

$$
(\mathrm{n}=157)
$$

- lrrelevant topics: $\mathrm{n}=72$

- non-comparative

studies: $\mathrm{n}=78$

- case report: $\mathrm{n}=4$

- review: $\mathrm{n}=3$

Full texts excluded

$$
(\mathrm{n}=8)
$$

- Complications except

for $\mathrm{MH}: \mathrm{n}=4$

- non-standard surgery:

$\mathrm{n}=2$

- non-anatomical or

visual outcome: $n=2$

Fig. 1 Flow diagram of the study selection process 


\section{Study characteristics}

The main characteristics of the included studies are listed in Table 1 . This review included 8 studies, 4 RCTs and 4 case series. It enrolled 578 patients with a total of 593 eyes, including 325 in the ILM peeling group and 268 in the inverted ILM flap group. Their mean age ranged from 59.37 to 69.9 years. The mean duration of symptoms varied from 3.06 to 20 months, and the average minimum diameter of $\mathrm{MH}$ ranged from 493.8 to $803.33 \mu \mathrm{m}$. The shortest follow-up duration was 3 months in 3 studies [4, 10, 12], the follow-up duration $\geq 6$ months in 5 studies $[9,11,13-15]$.

\section{Quality assessment}

We assessed the quality of the 4 RCTs using cochrane collaboration's tool. Methodological quality of eligible trials was moderate to good, and is explained comprehensively in Table 2. The included RCTs had low risk of bias in general, which only had 1 or 2 items with" unknown risk of bias", except the study reported by Velez-Montoya et al. [4] that had low risk of bias in all assessing criteria and was assessed as a high-quality trial. Double-blinding and reporting outcomes completely were not mentioned in parts of trials, which suggested that the results might be affected slightly by performance bias and selective bias. Of the 4 case series included for quality assessment based on NOS, all studies met 6 or more stars out of 9. All participants included in the case series measured the conditions in a standard and reliable manner. The selection of cases and comparability between case and control trials were clearly reported. The qualitative assessment of case series is presented in Table 3.

\section{The rate of macular hole closure rate analysis}

All the included studies reported the rate of $\mathrm{MH}$ closure after treated with ILM peeling or inverted ILM flap technique. The rate of MH closure was 92.5\% (248/268 eyes) in the inverted ILM flap technique group and 87.4\% (284/ 325 eyes) in the ILM peeling group. These results suggested that the $\mathrm{MH}$ closure rate wasn't significantly different between two groups $(\mathrm{OR}=2.23,95 \% \mathrm{CI}=0.80$ to $6.22 ; P=$ 0.12; Fig. 2). However, there revealed a moderate heterogeneity between these studies (heterogeneity $\mathrm{I}^{2}=48 \%$ ).

For further clarifying the source of heterogeneity, we performed sensitivity analysis to determine whether existing statistics were stable. Sensitivity analysis were conducted by deleting each included study step by step, and revealed that the trial reported by Iwasaki et al. [14] produce the significantly affect the pooled result, which was considered to be the source heterogeneity. When this trial was removed, there was no statistical heterogeneity between all other studies (heterogeneity $\mathrm{I}^{2}=0 \%$ ). The meta-analysis of pooled data showed $\mathrm{MH}$ closure with inverted ILM flap technique group was statistically significantly higher than ILM peeling group $(\mathrm{OR}=3.95$, $95 \% \mathrm{CI}=1.89$ to 8.27 ; $P=0.0003$; Fig. 3 ).

\section{Preoperative visual acuity analysis}

One [9] of the eight trials didn't report standard deviation (SD) of preoperative VA after vitrectomy, thus the remaining seven trials were included. The forest plots of preoperative VA revealed that the differences were not statistically significant between the inverted ILM flap technique group and ILM peeling group (MD $=-0.03$, $95 \% \mathrm{CI}=-0.09$ to $0.02 ; P=0.23$; Fig. 4 ). There was mild statistical heterogeneity between the studies

Table 1 Study characteristics of eligible clinical studies

\begin{tabular}{|c|c|c|c|c|c|c|c|c|c|c|c|c|c|}
\hline Study & Year & Country & Trial type & Group & $\begin{array}{c}\text { No. of } \\
\text { eye }\end{array}$ & $\begin{array}{c}\text { No. of } \\
\text { patients }\end{array}$ & Age (yr) & $\begin{array}{l}\text { Duration of } \\
\text { MH (months) }\end{array}$ & $\begin{array}{l}\text { Minimum diameter } \\
\text { of } \mathrm{MH}(\mu \mathrm{m})\end{array}$ & $\begin{array}{l}\text { Hole closure } \\
\text { rate }(\%)\end{array}$ & $\begin{array}{c}\text { Pre-VA } \\
\operatorname{logMAR} \pm \text { SD }\end{array}$ & $\begin{array}{c}\text { Post-VA } \\
\operatorname{logMAR} \pm \text { SD }\end{array}$ & $\begin{array}{c}\text { Follow up } \\
\text { (month) }\end{array}$ \\
\hline \multirow{2}{*}{$\begin{array}{l}\text { Michal ewska } \\
\text { et al. } \\
\text { [9] }\end{array}$} & \multirow{2}{*}{2010} & \multirow{2}{*}{ Poland } & \multirow{2}{*}{$\begin{array}{l}\text { A randomized } \\
\text { control trial }\end{array}$} & ILM peeling & 51 & $40(8 \mathrm{~m}, 32 \mathrm{f})$ & 65 & 19 & 698 & 88 & 0.92 & 0.77 & 12 \\
\hline & & & & Inverted ILM flap & 50 & $46(13 m, 33 f)$ & 66 & 20 & 759 & 98 & 1. 11 & 0.55 & 12 \\
\hline \multirow{2}{*}{$\begin{array}{c}\text { Manasa S } \\
\text { et al. } \\
\text { [10] }\end{array}$} & \multirow{2}{*}{2018} & \multirow{2}{*}{ India } & \multirow{2}{*}{$\begin{array}{l}\text { A randomized } \\
\text { control trial }\end{array}$} & ILM peeling & 48 & $48(22 \mathrm{~m}, 26 \mathrm{f})$ & 60.95 & 12.58 & 657.5 & 87.5 & $1.1 \pm 0.28$ & $0.86 \pm 0.19$ & 3 \\
\hline & & & & Inverted ILM flap & 43 & $43(20 \mathrm{~m}, 23 \mathrm{f})$ & 63.41 & 11.39 & 673 & 95.35 & $0.99 \pm 0.25$ & $0.67 \pm 0.3$ & 3 \\
\hline \multirow{2}{*}{$\begin{array}{c}\text { Kannan N B } \\
\text { et al. } \\
\text { [11] }\end{array}$} & \multirow{2}{*}{2018} & \multirow{2}{*}{ India } & \multirow{2}{*}{$\begin{array}{l}\text { A randomized } \\
\text { control trial }\end{array}$} & ILM peeling & 30 & $30(17 \mathrm{~m}, 13 \mathrm{f})$ & $61.17 \pm 7.42$ & $\mathrm{NA}$ & $759.97 \pm 85.01$ & 76.7 & $0.79 \pm 0.24$ & $0.65 \pm 0.25$ & 6 \\
\hline & & & & Inverted ILM flap & 30 & $30(11 \mathrm{~m}, 19 \mathrm{f})$ & $59.37 \pm 6.71$ & $\mathrm{NA}$ & 803. $33 \pm 120.65$ & 90 & $0.75 \pm 0.22$ & $0.53 \pm 0.20$ & 6 \\
\hline \multirow{2}{*}{$\begin{array}{c}\text { Velez-Monto } \\
\text { ya R et al. } \\
\text { [4] }\end{array}$} & \multirow{2}{*}{2018} & \multirow{2}{*}{ Mexico } & \multirow{2}{*}{$\begin{array}{l}\text { A randomized } \\
\text { control trial }\end{array}$} & ILM peeling & 12 & 12 & $61.8 \pm 9.6$ & $3.85 \pm 1.8$ & $522.22 \pm 82.73$ & 91.67 & $0.925 \pm 0.5$ & $0.707 \pm 0.3$ & 3 \\
\hline & & & & Inverted ILM flap & 12 & 12 & $64.2 \pm 6.7$ & $3.06 \pm 1.8$ & $608.89 \pm 213$ & 91.67 & $0.953 \pm 0.2$ & $0.616 \pm 0.2$ & 3 \\
\hline \multirow{2}{*}{$\begin{array}{l}\text { Pak K Y } \\
\text { et al. } \\
\text { [12] }\end{array}$} & \multirow{2}{*}{2017} & \multirow{2}{*}{ Korea } & \multirow{2}{*}{$\begin{array}{l}\text { A retrospective } \\
\text { case series }\end{array}$} & ILM peeling & 51 & $51(17 \mathrm{~m}, 34 \mathrm{f})$ & $66.1 \pm 6.6$ & $3.9 \pm 5.2$ & $558.9 \pm 106.8$ & 88.2 & $1.00 \pm 0.33$ & $0.63 \pm 0.29$ & 3 \\
\hline & & & & Inverted ILM flap & 41 & $41(9 \mathrm{~m}, 32 \mathrm{f})$ & $65.7 \pm 7.5$ & 4. $1 \pm 4.8$ & $590.8 \pm 113.1$ & 100 & $0.92 \pm 0.26$ & $0.48 \pm 0.22$ & 3 \\
\hline \multirow{2}{*}{$\begin{array}{c}\text { Yamashita T } \\
\text { et al. } \\
\text { [13] }\end{array}$} & \multirow{2}{*}{2018} & \multirow{2}{*}{ Japan } & \multirow{2}{*}{$\begin{array}{l}\text { A retrospective } \\
\text { case series }\end{array}$} & ILM peeling & 105 & 105 & $\mathrm{NA}$ & $\mathrm{NA}$ & $544 \pm 119$ & 92.4 & $0.94 \pm 0.31$ & $0.44 \pm 0.34$ & 6 \\
\hline & & & & Inverted ILM flap & 60 & 60 & $\mathrm{NA}$ & $\mathrm{NA}$ & $624 \pm 128$ & 100 & $0.98 \pm 0.30$ & $0.51 \pm 0.34$ & 6 \\
\hline \multirow{2}{*}{$\begin{array}{c}\text { Iwasaki M } \\
\text { et al. } \\
\text { [14] }\end{array}$} & \multirow{2}{*}{2018} & \multirow{2}{*}{ Japan } & \multirow{2}{*}{$\begin{array}{l}\text { A retrospective } \\
\text { case series }\end{array}$} & ILM peeling & 10 & $10(2 \mathrm{~m}, 8 \mathrm{f})$ & $69.9 \pm 6.6$ & $\mathrm{NA}$ & $551.1 \pm 99.5$ & 70 & $0.86 \pm 2.4$ & $0.41 \pm 0.31$ & $9.5 \pm 4.3$ \\
\hline & & & & Inverted ILM flap & 14 & $14(5 \mathrm{~m}, 9 \mathrm{f})$ & $65.4 \pm 9.0$ & $\mathrm{MA}$ & $655.2 \pm 112.1$ & 21.4 & $0.85 \pm 0.33$ & $0.67 \pm 0.38$ & $10.4 \pm 4.1$ \\
\hline \multirow{2}{*}{$\begin{array}{l}\text { Narayanan R } \\
\text { et al. } \\
\text { [15] }\end{array}$} & \multirow{2}{*}{2018} & \multirow{2}{*}{ St Louis } & \multirow{2}{*}{$\begin{array}{l}\text { A retrospective } \\
\text { case series }\end{array}$} & ILM peeling & 18 & $18(8 \mathrm{~m}, 10 \mathrm{f})$ & $67.50 \pm 7.78$ & 8.83 & $493.8 \pm 170.5$ & 77.8 & $0.98 \pm 0.22$ & $0.82 \pm 0.23$ & 6 \\
\hline & & & & Inverted ILM flap & 18 & $18(5 \mathrm{~m}, 13 \mathrm{f})$ & $60.22 \pm 12.09$ & 8.61 & $577.4 \pm 159.4$ & 88.9 & $1.13 \pm 0.66$ & $0.77 \pm 0.30$ & 6 \\
\hline
\end{tabular}

ILM internal limiting membrane, $m$ male, $f$ female, $N A$ not available, $M H$ macular hole, VA visual acuity, logMAR logarithm of minimal angle of resolution, $S D$ standard deviation 
Table 2 Summary of "risk of bias" assessment

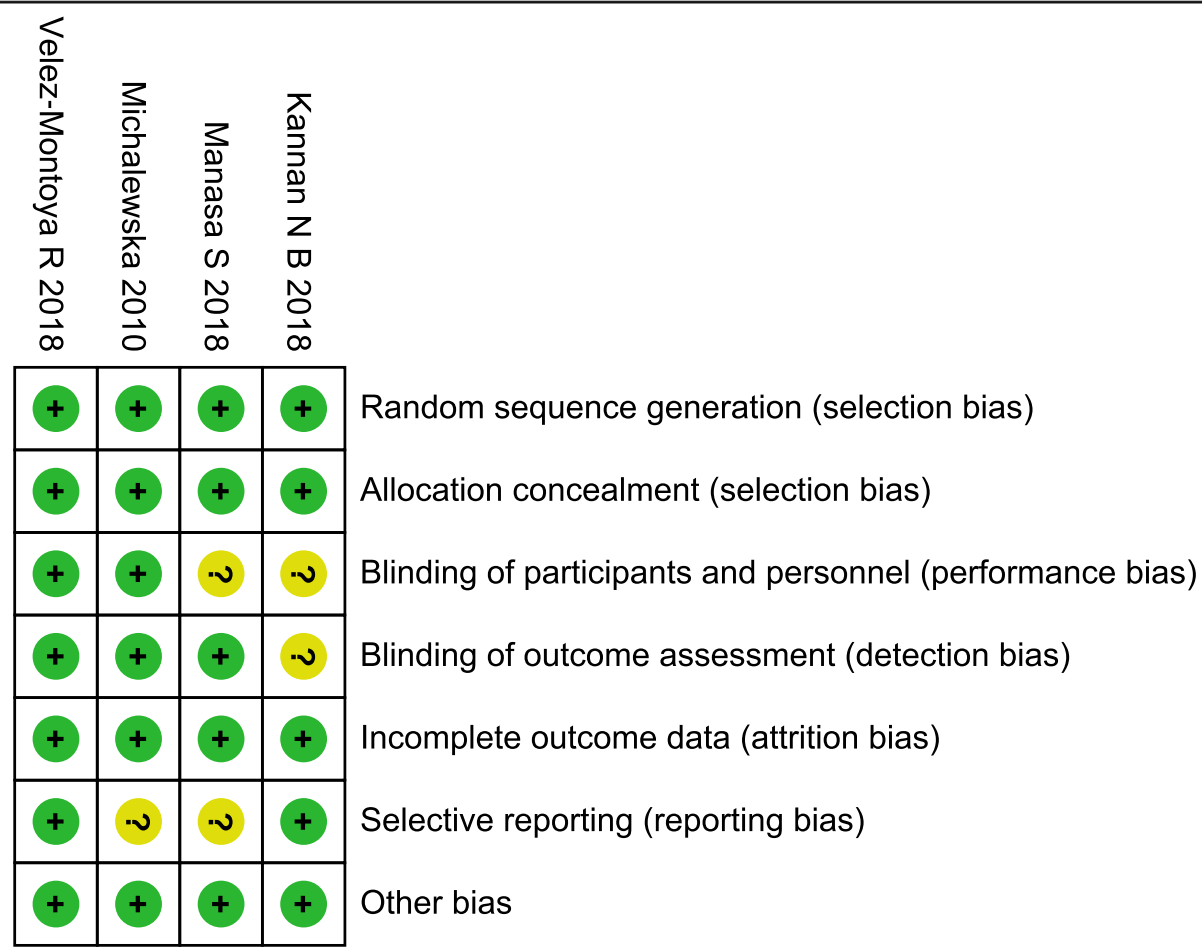

The Cochrane "risk of bias" tool was used for quality assessment. Green for "yes" and yellow for "unclear

(heterogeneity $\mathrm{I}^{2}=2 \%$ ), of which influence to the pooled result could be neglected.

\section{Postoperative visual acuity analysis}

To analysis the results of comparing postoperative VA between the group of inverted ILM flap technique and ILM peeling, we included the seven trials all reported the postoperative VA after surgery except one trial [9] that didn't mentioned SD of postoperative VA. There was no statistically significant difference in postoperative
VA between two groups $(\mathrm{MD}=-0.06,95 \% \mathrm{CI}=-0.16$ to $0.03 ; P=0.19 ;$ Fig. 5$)$. However, Heterogeneity was relatively high (heterogeneity $\mathrm{I}^{2}=70 \%$ ).

In order to eliminate the effect of follow-up time to the result, We carried out the subgroup analysis based on follow-up duration that divided the included studies into follow-up duration at 3 months and follow-up duration $\geq 6$ months. In the subgroup analysis of follow-up duration at 3 months including 3 studies $[4,10,12]$, postoperative VA was significantly

Table 3 Newcastle-Ottawa Scale table

\begin{tabular}{|c|c|c|c|c|}
\hline \multicolumn{5}{|c|}{ Newcastle-0ttawa Scale (NOS) } \\
\hline Study & Selection & Comparability & Exposure & Total \\
\hline $\begin{array}{l}\text { Pak K Y } \\
2017 \quad[12]\end{array}$ & 2 & 2 & 2 & 6 \\
\hline $\begin{array}{c}\text { Yamashita T } \\
2018 \text { [13] }\end{array}$ & 3 & 2 & 1 & 6 \\
\hline $\begin{array}{l}\text { Iwasaki M } \\
2018 \quad[14]\end{array}$ & 3 & 2 & 1 & 6 \\
\hline $\begin{array}{c}\text { Narayanan R } \\
2018 \text { [15] }\end{array}$ & 3 & 2 & 2 & 7 \\
\hline
\end{tabular}




\begin{tabular}{|c|c|c|c|c|c|c|c|c|c|c|}
\hline \multirow[b]{2}{*}{ Study or Subgroup } & \multicolumn{2}{|c|}{ Inverted ILM flap } & \multicolumn{2}{|c|}{ ILM peeling } & \multirow[b]{2}{*}{ Weight } & \multirow{2}{*}{$\begin{array}{l}\text { Odds Ratio } \\
\text { M-H. Random, } 95 \% \mathrm{Cl}\end{array}$} & \multirow{2}{*}{\multicolumn{4}{|c|}{$\begin{array}{c}\text { Odds Ratio } \\
\mathrm{M}-\mathrm{H} \text {. Random, } 95 \% \mathrm{Cl}\end{array}$}} \\
\hline & Events & Total & Events & Total & & & & & & \\
\hline Iwasaki M 2018 & 3 & 14 & 7 & 10 & $14.3 \%$ & $0.12[0.02,0.75]$ & & . & & \\
\hline Kannan N B 2018 & 27 & 30 & 23 & 30 & $17.4 \%$ & $2.74[0.63,11.82]$ & & & & \\
\hline Manasa S 2018 & 41 & 43 & 42 & 48 & $15.8 \%$ & $2.93[0.56,15.36]$ & & & & \\
\hline Michalewska 2010 & 49 & 50 & 45 & 51 & $12.3 \%$ & $6.53[0.76,56.39]$ & & & & \\
\hline Narayanan R 2018 & 16 & 18 & 14 & 18 & $14.4 \%$ & $2.29[0.36,14.43]$ & & & - & \\
\hline Pak K Y 2017 & 41 & 41 & 45 & 51 & $8.5 \%$ & $11.86[0.65,217.02]$ & & & & \\
\hline Velez-Montoya R 2018 & 11 & 12 & 11 & 12 & $8.6 \%$ & $1.00[0.06,18.08]$ & & & & \\
\hline Yamashita T 2018 & 60 & 60 & 97 & 105 & $8.7 \%$ & $10.55[0.60,186.08]$ & & & & \\
\hline Total $(95 \% \mathrm{Cl})$ & & 268 & & 325 & $100.0 \%$ & $2.23[0.80,6.22]$ & & & & \\
\hline Total events & 248 & & 284 & & & & & & & \\
\hline $\begin{array}{l}\text { Heterogeneity: } \text { Tau }^{2}=1 \\
\text { Test for overall effect: } Z\end{array}$ & $\begin{array}{l}\text { 1) } \mathrm{Ch}^{2}=13 \\
=1.54(\mathrm{P}=0\end{array}$ & $\begin{array}{l}3, d f=7 \\
\text { 2) }\end{array}$ & $(P=0.0$ & ;); $1^{2}=4$ & & & $\begin{array}{r}0.005 \\
\text { Fa। }\end{array}$ & $\begin{array}{ll}0.1 & 1 \\
\text { [experimental] }\end{array}$ & $\begin{array}{cc}1 & 10 \\
& \text { Favours [control] }\end{array}$ & 200 \\
\hline
\end{tabular}

better in the group of inverted ILM flap than ILM peeling $(\mathrm{MD}=-0.16,95 \% \mathrm{CI}=-0.23$ to $0.09 ; P<$ 0.00001 ; Fig. 6). We observed no heterogeneity between 3 studies in the subgroup of follow-up duration at 3 months (heterogeneity $\mathrm{I}^{2}=0 \%$ ). The analysis of a subgroup with a longer follow-up period did not show any statistically significant differences between the group of inverted ILM flap technique and ILM peeling ( $\mathrm{MD}=0.01,95 \% \mathrm{CI}=-0.12$ to $0.15 ; P=0.86$; Fig. 6). Moreover, there was still high heterogeneity between these trials in the subgroup of follow-up duration $\geq 6$ months (heterogeneity $\mathrm{I}^{2}=68 \%$ ). After reading the included four studies $[11,13-15]$ carefully, a random effects model was used in the later subgroup.

\section{Publication bias analysis}

Two funnel plots of the rate of $\mathrm{MH}$ closure, the preoperative VA showed that the scattered points of the included studies were distributed in the middle and top of the baseline, and most points were located in the range of inverted funnel. It suggested that there was no serious publication bias and the conclusion is relatively reliable (Figs. 7, 8).

\section{Discussion}

We conducted this systematic review and double arm meta-analysis of literature to summarize current evidence and compare the anatomical and visual outcomes of vitrectomy with inverted ILM flap technique and ILM peeling. After pooling the results of the rate of $\mathrm{MH}$ closure in these included studies, we performed sensitivity analysis to find the source of heterogeneity. This study [14] was considered to be remove, because its limitations included small sample size, non-standardized measurements, the presence of multiple surgeons, the utilization of multiple OCT machines, and so on. After eliminating the interference of heterogeneity, the result indicated that the rate of $\mathrm{MH}$ closure was significantly higher in vitrectomy with inverted ILM flap than that in vitrectomy with ILM peeling.

In histopathologic findings, when the margins of the ILM were left attached to the edges of the hole, it served as a gap-free natural scaffold for gliosis, and provided a basement membrane for proliferateglial glial cells to maintain anatomic structure of the foveola $[9,10]$. Shiode et al. showed that the neurotrophic factors and basic fibroblast growth factors (bFGF) on the surface of the ILM flap promoted the proliferation and migration

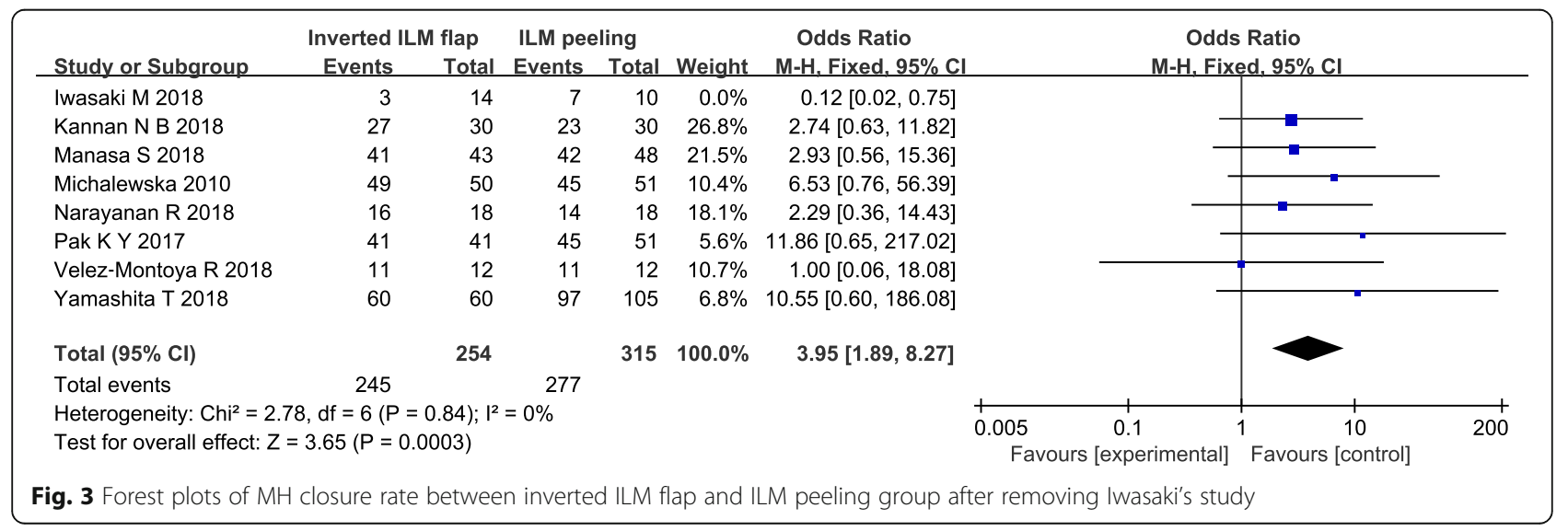




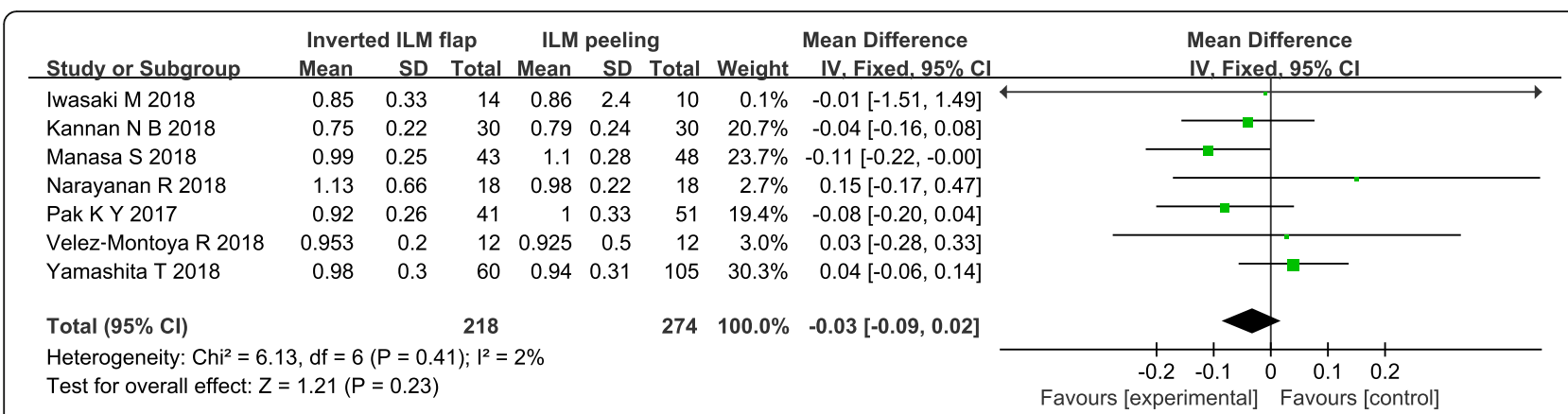

Fig. 4 Forest plots of preoperative VA between inverted ILM flap and ILM peeling group. Michalewska's study was not included in the analysis of preoperative VA due to the SD of preoperative VA was not given

of the Müller cells, contributing to fill the $\mathrm{MH}$ and enhance closure [11]. Activated Müller cells also produced neurotrophic factors and growth factors that may promote the survival of retinal neurons [18]. Moreover, the ILM flaps create a closed compartment enabling the RPE to pump out fluid and keep hole dry [10]. These findings explained to the better anatomical results in the inverted ILM flap technique group.

As for the outcomes of visual functions, the preoperative and postoperative VA were observation indexes in this review. There were not significant in the preoperative VA between the two groups, which reduced preintervention effects to postoperative VA. Considering the heterogeneity in postoperative VA between these trials, the included studies divided into two subgroups based upon follow-up duration to observe the short and long-term visual efficacy. Compared with ILM peeling, postoperative VA was better in the group of inverted ILM flap technique at the follow-up of 3 months. It seemed that flap technique had a signifcant visual gain in the short term. It was believed that the ILM flaps was also a bridge leading photoreceptor to migrate into the retina defect [19]. Michalewska et al. [9] found that glial cells proliferated and produced an environment to transfer light from the retinal surface to the photoreceptor cell layer. In the cases after the surgery of inverted ILM flap technique, retinal tissue regenerated from the external limiting membrane (ELM), then regrowth of the ellipsoid layer was observed over the next few months $[4,20]$.

However, contrary to expectation, our results indicated no difference in functional outcomes between the two groups of different surgical treatments at relatively longterm follow-up over 6 months. Hayashi et al. [21] suggested that the photoreceptor layer of fovea might be destroyed and had irreversible damage. Ota et al. [22] showed the fovea losed its original stratified structure in large MH. The IS/OS and ELM would returned gradually after surgery, but not completely or in all cases. The improvement of the foveal structure did not include the restoration of the normal layered structure of retina. There were no significant differences in structural changes over time after inverted ILM flap technique or ILM peeling. Moreover, the differences in the baseline characteristics such as $\mathrm{MH}$ size related to the results $[14,22]$. These findings might explain the limitations in visual recovery after vitrectomy with inverted ILM flap technique at a longer follow-up.

For all we know, double-arm study to compare the efficacy in large $\mathrm{MH}$ after treatments between inverted ILM flap technique and ILM peeling was reviewed and analyzed firstly in this meta-analysis. However, several

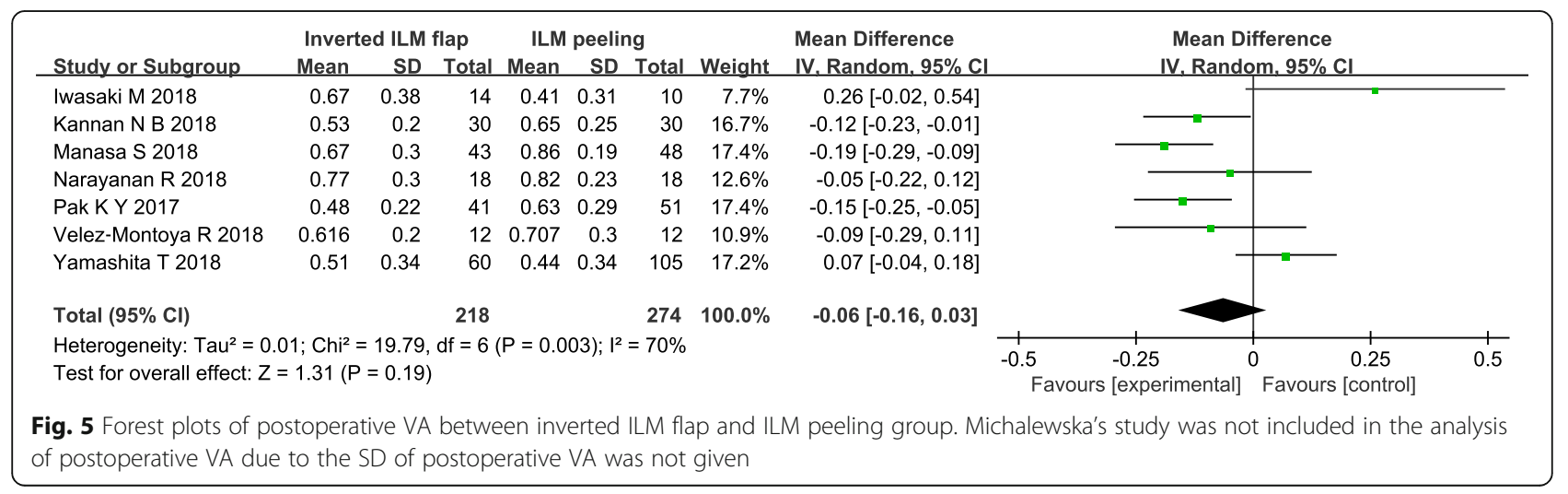




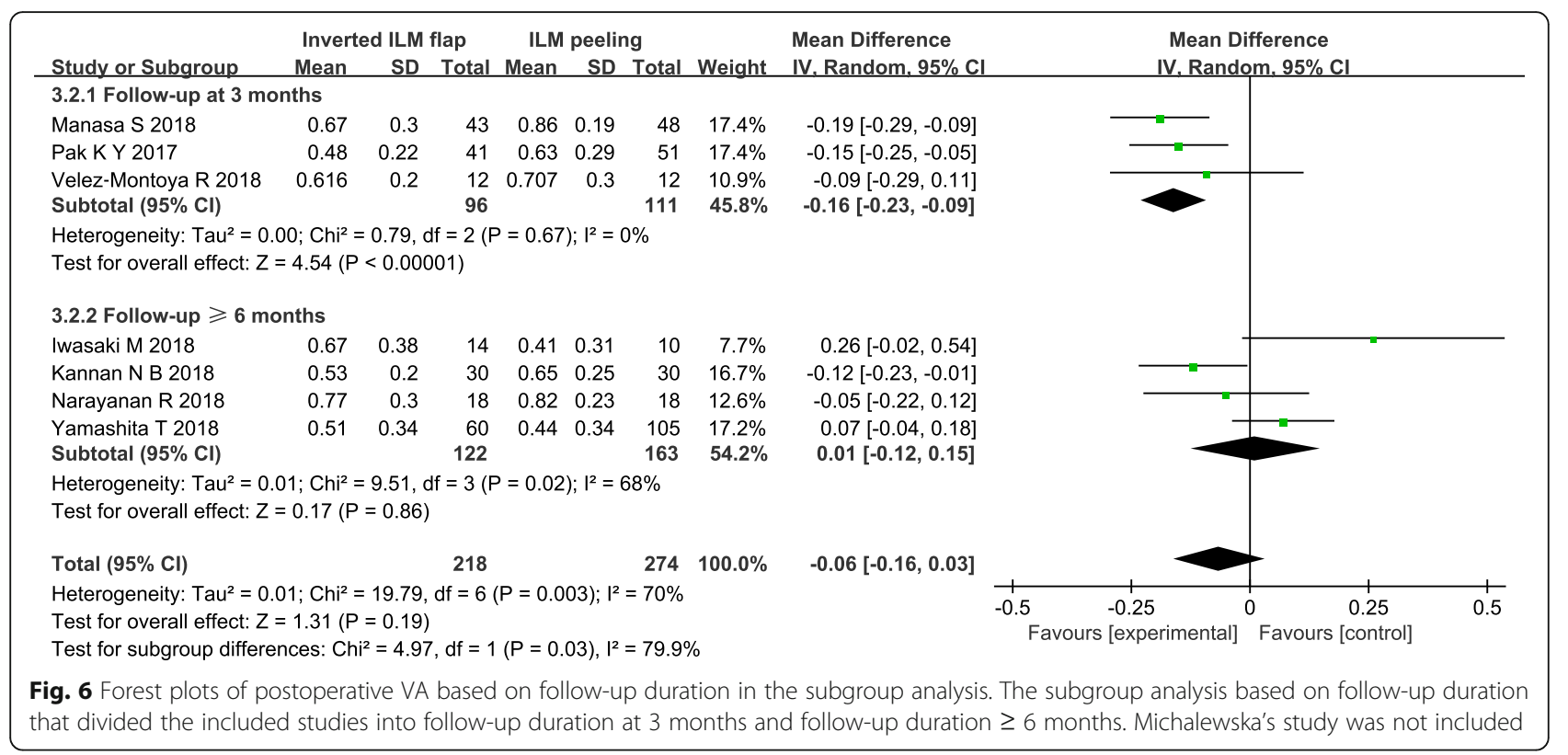

limitations were inevitable and should be taken into account when citing the results of the meta-analysis. First, the number of included studies and available data were limited. Second, this systematic review included not only RCTs but also retrospective studies, which might have potential sources of selection bias. Third, significant heterogeneity among the studies was detected in the comparison of primary and secondary end points. We alleviated but not eliminated completely the heterogeneity through sensitivity analysis and subgroup analysis.
The pooled data were from the relative long-term follow-up durations of the studies, introducing a potential heterogeneity. Follow-up durations in the included trials were not long enough for better observations of VA recovery in long term. Furthermore, other influence factors, such as dye for ILM stained or the specific forms of inverted ILM flap technique among the studies might serve as the points of heterogeneity. Due to the deficiency of these available data, we did not perform subgroup analysis.

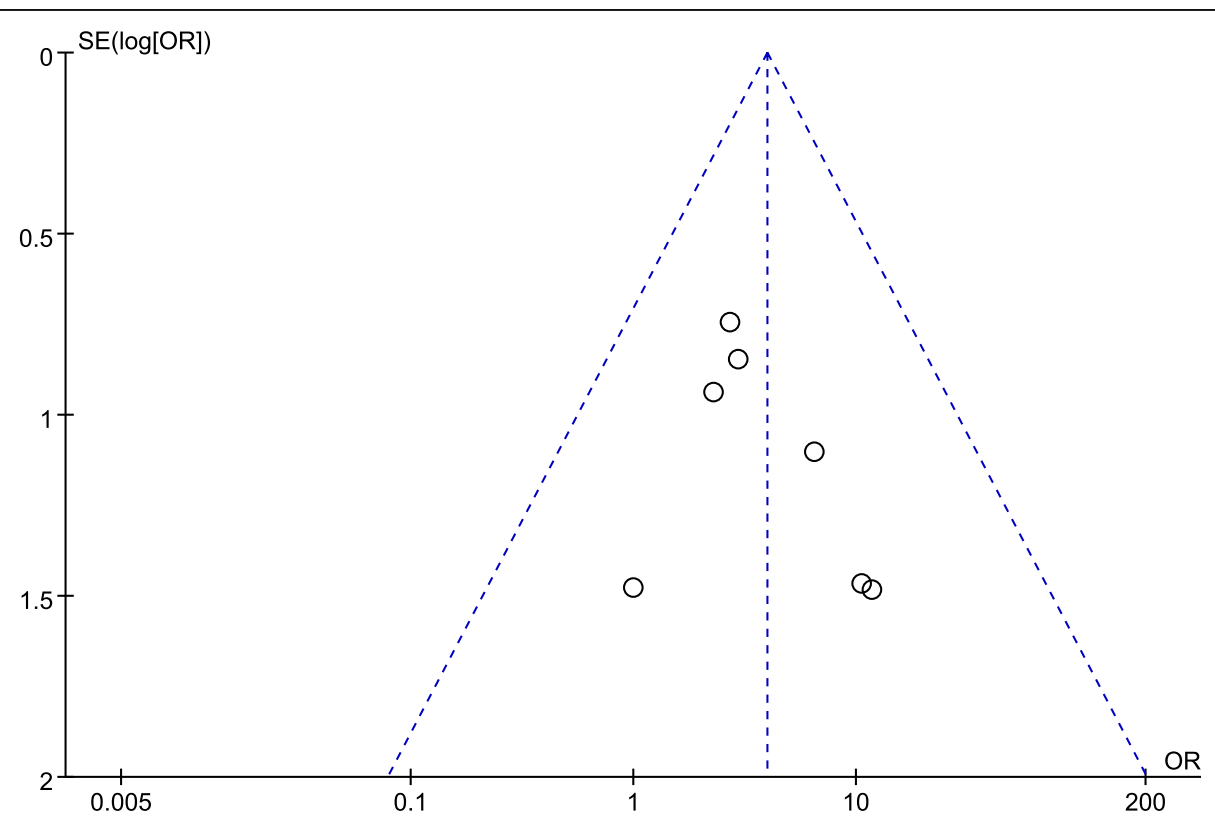

Fig. 7 Funnel plot analysis of $\mathrm{MH}$ closure rate. SE standard error, OR odds ratio 


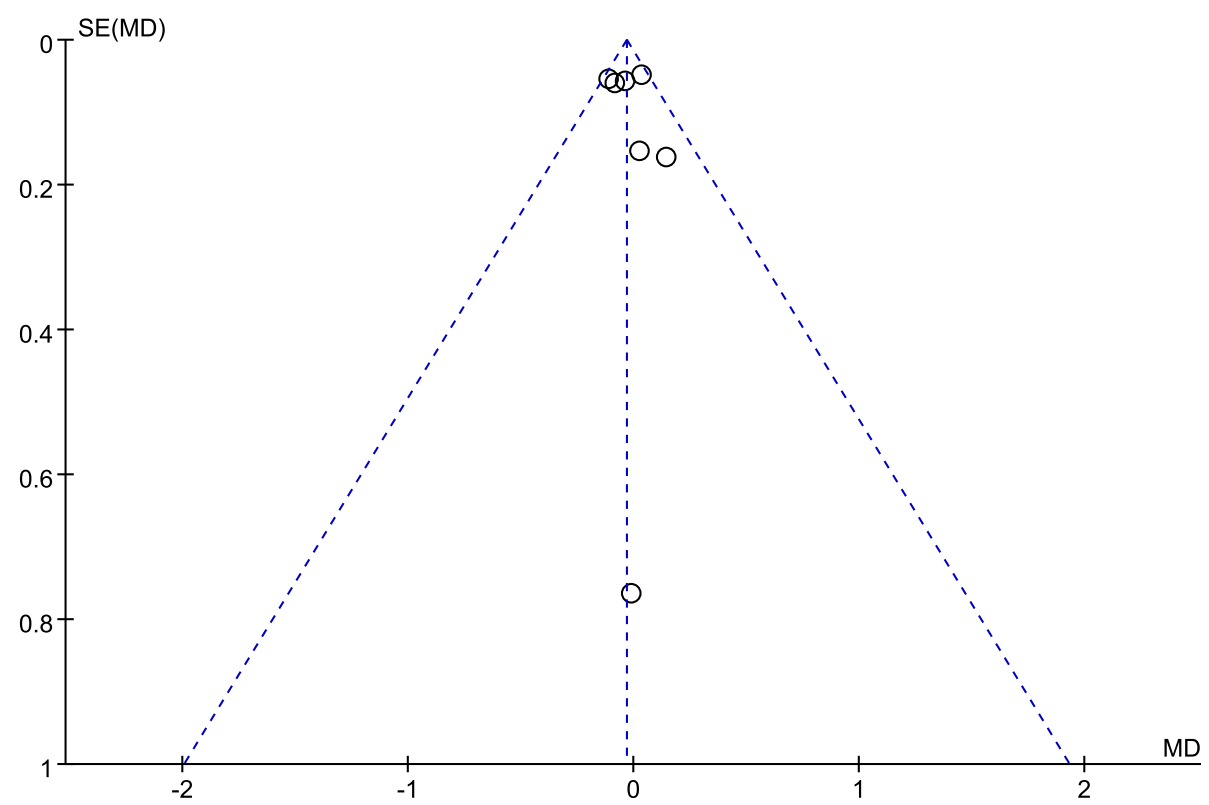

Fig. 8 Funnel plot analysis of preoperative VA

\section{Conclusions}

Our meta-analysis indicated that vitrectomy with inverted ILM flap technique had a better anatomical outcome than ILM peeling in large MH. Flap technique had a signifcant visual gain in the short term, but the limitations in visual recovery at a longer follow-up was found. Moreover, there is an urgent need for long follow-up duration and large prospective randomized study to further confirm the efficacy of inverted ILM flap technique and ILM peeling.

\section{Abbreviations}

bFGF: Basic fibroblast growth factors; Cl: Confidence interval; ELM: External limiting membrane; ILM: Internal limiting membrane; logMAR: Logarithm of minimal angle of resolution; MD: Mean difference; MH: Macular hole; MH: Mantel-Haenszel; NOS: Newcastle-Ottawa Scale; OR: Odds ratio; RCT: Randomized control trial; SD: Standard deviation; SE: Standard error; VA: Visual acuity

\section{Acknowledgements}

Not applicable.

\section{Authors' contributions}

Conceived and designed the study: YS and MQW; Acquisition of data: YS and XQL; Analysis and interpretation of data: YS and XQL; Drafting the. manuscript: YS and LYZ; Revising the manuscript critically for important. intellectual content: LYZ and MQW. All authors read and approved the final. manuscript.

\section{Funding}

This project was supported by Zhejiang Province Science and Technology Department, China (2014C03042-1) and Natural Science Foundation for Young Scholars of Zhejiang Province, China (LQ19H120005). The funders had no role in the design of the study and collection, analysis, and interpretation of data and in writing the manuscript.

\section{Availability of data and materials}

The data that support the findings of this study are available in the reference $[4,9-15]$.
Ethics approval and consent to participate

Not applicable.

\section{Consent for publication}

Not applicable.

\section{Competing interests}

The authors declare that they have no competing interests.

\section{Author details}

'Second Clinical Medicine Faculty, Zhejiang Chinese Medical University, Hangzhou 310053 Zhejiang Province, People's Republic of China. 2Department of Ophthalmology, Zhejiang Provincial People's Hospital, People's Hospital of Hangzhou Medical college, Hangzhou 310014 Zhejiang Province, People's Republic of China.

Received: 18 June 2019 Accepted: 18 October 2019

Published online: 08 January 2020

References

1. Kelly NE, Wendel RT. Vitreous surgery for idiopathic macular holes results of a pilot study. Arch Ophthalmol. 1991;109:654-9.

2. Beutel J, Dahmen G, Ziegler A, Hoerauf H. Internal limiting membrane peeling with indocyanine green or trypan blue in macular hole surgery: a randomized trial. Arch Ophthalmol. 2007;125(3):326-32.

3. Andrew N, Chan WO, Tan M, Ebneter A, Gilhotra JS. Modifcation of the inverted internal limiting membrane fap technique for the treatment of chronic and large macular holes. Retina. 2016;36(4):834-7.

4. Velez-Montoya R, Ramirez-Estudillo JA, Sjoholm-Gomez de Liano C, BejarCornejo F, Sanchez-Ramos J, Guerrero-Naranjo JL, Morales-Canton V, Hernandez-Da Mota SE. Inverted ILM flap, free ILM flap and conventional ILM peeling for large macular holes[J]. Int J Retina Vitreous. 2018;4(1):8.

5. Eckardt CL, Eckardt U, Groos ST, Luciano LI, Reale EN. Removal of the internal limiting membrane in macular holes. Clinical and morphological findings. Ophthalmologe. 1997;94(8):545-51.

6. Williamson TH, Lee E. Idiopathic macular hole: analysis of visual outcomes and the use of indocyanine green or brilliant blue for internal limiting membrane peel. Graefes Arch Clin Exp Ophthalmol. 2014;252:395-400.

7. Kase S, Saito W, Mori S, Saito M, Ando R, Dong Z, Suzuki T, Noda K, Ishida S. Clinical and histological evaluation of large macular hole surgery using the inverted internal limiting membrane fap technique. Clin Ophthalmol. 2017; 11:9-14. 
8. Hussain N, Hussain A. Successful closure of treatment-naive, fat edge (type II), full-thickness macular hole using inverted internal limiting membrane fap technique. Int Med Case Rep J. 2016;9:313-6.

9. Michalewska Z, Michalewski J, Adelman RA, Nawrocki J. Inverted internal limiting membrane flap technique for large macular holes. Ophthalmol. 2010;117:2018-25.

10. Manasa S, Kakkar P, Kumar A, Chandra P, Kumar V, Ravani R. Comparative evaluation of standard ILM Peel with inverted ILM flap technique in large macular holes: a prospective, randomized study. Ophthalmic Surg Lasers Imaging Retina. 2018;49(4):236.

11. Kannan NB, Kohli P, Parida H, Adenuga OO, Ramasamy K. Comparative study of inverted internal limiting membrane (ILM) flap and ILM peeling technique in large macular holes: a randomized-control trial. BMC Ophthalmol. 2018;18(1):177.

12. Pak KY, Park JY, Park SW, Byon IS, Lee JE. Efficacy of the Perfluoro-N-octaneassisted single-layered inverted internal limiting membrane flap technique for large macular holes. Ophthalmologica. 2017;238(3):133-8.

13. Yamashita T, Sakamoto T, Terasaki H, Iwasaki M, Ogushi Y, Okamoto F, Takeuchi M, Yasukawa T, Takamura Y, Ogata N, Nakamura Y. Writing committee of Japan-clinical retina research team (J-CREST). Best surgical technique and outcomes for large macular holes: retrospective multicentre study in Japan. Acta Ophthalmol. 2018:96(8):e904-10.

14. Iwasaki M, Kinoshita T, Miyamoto $\mathrm{H}$, Imaizumi $\mathrm{H}$. Influence of inverted internal limiting membrane flap technique on the outer retinal layer structures after a large macular hole surgery. Retina. 2018:1-8.

15. Narayanan R, Singh SR, Taylor S, Berrocal MH, Chhablani J, Tyagi M, OhnoMatsui K, Pappuru RR, Apte RS. SURGICAL OUTCOMES AFTER INVERTED INTERNAL LIMITING MEMBRANE FLAP VERSUS CONVENTIONAL PEELING FOR VERY LARGE MACULAR. HOLES Retina 2018;39(8):1465-1469. https://doi.org/ https://doi.org/10.1097/IAE.0000000000002186.

16. Shuster JJ. Review: Cochrane handbook for systematic reviews for interventions, version 5.1.0, published 3/2011. Julian P.T. Higgins and Sally green, editors. Res Synth Methods. 2011;2(2):126-30.

17. Hartling L, Milne A, Hamm MP, Vandermeer B, Ansari M, Tsertsvadze A, Dryden DM. Testing the Newcastle Ottawa scale showed low reliability between individual reviewers. J Clin Epidemiol 2013;66(9):982-993. https:// doi.org/https://doi.org/10.1016/j.jclin epi.2013.03.003.

18. Shiode Y, Morizane Y, Matoba R, Hirano M, Doi S, Toshima S, Takahashi K, Araki R, Kanzaki Y, Hosogi M, Yonezawa T, Yoshida A, Shiraga F. The role of inverted internal limiting membrane flap in macular hole closure. Invest Ophthalmol Vis Sci. 2017;58(11):4847-55.

19. Morizane Y, Shiraga F, Kimura S, Hosokawa M, Shiode Y, Kawata T, Hosogi $M$, Shirakata Y, Okanouchi T. Autologous transplantation of the internal limiting membrane for refractory macular holes. Am J Ophthalmol. 2014; 157(4):861-9.

20. Bonińska K, Nawrocki J, Michalewska Z. Mechanism of "flap closure" after the inverted internal limiting membrane flap technique. Retina. 2018;38(11): 2184-2189. https://doi.org/https://doi.org/10.1097/AAE.0000000000001861.

21. Hayashi H, Kuriyama S. Foveal microstructure in macular holes surgically closed by inverted internal limiting membrane flap technique. Retina. 2014; 34:2444-50.

22. Ota $\mathrm{H}$, Kunikata $\mathrm{H}$, Aizawa $\mathrm{N}$, Nakazawa T. Surgical results of internal limiting membrane flap inversion and internal limiting membrane peeling for macular hole. PLoS One. 2018;13:e0203789.

\section{Publisher's Note}

Springer Nature remains neutral with regard to jurisdictional claims in published maps and institutional affiliations.

Ready to submit your research? Choose BMC and benefit from:
- fast, convenient online submission
- thorough peer review by experienced researchers in your field
- rapid publication on acceptance
- support for research data, including large and complex data types
- gold Open Access which fosters wider collaboration and increased citations
- maximum visibility for your research: over 100M website views per year
At BMC, research is always in progress.
Learn more biomedcentral.com/submissions

